\title{
A New Genus and a New Species of the Scopariinae Guinée, 1854 (Lepidoptera: Crambidae) from the Southern Arabian Peninsula
}

\author{
Michael Seizmair \\ Department of Entomology, Section Lepidoptera, Bavarian State Collection of Zoology Munich, Munich, Germany
}

Email address:

michael.seizmair@gmx.net

\section{To cite this article:}

Michael Seizmair. A New Genus and a New Species of the Scopariinae Guinée, 1854 (Lepidoptera: Crambidae) from the Southern Arabian Peninsula. American Journal of Entomology. Vol. 4, No. 3, 2020, pp. 51-57. doi: 10.11648/j.aje.20200403.12

Received: October 22, 2020; Accepted: November 6, 2020; Published: November 16, 2020

\begin{abstract}
New taxonomic and faunistic results on the Scopariinae Guinée, 1854 (Lepidoptera: Crambidae) are presented on the basis of a sample of four specimens collected by the author in three research expeditions to the south-western province Dhofar of Oman in the years 2018 and 2019. The attribution of the material to the subfamily Scopariinae Guinée, 1854 was done on the basis of characteristic elements in the forewing pattern known as the scopariine wing pattern. Examination of the male and female genitalia revealed significant morphological differences between the specimens of the sample and the type species of all the other genera of the subfamily Scopariinae Guinée, 1854. These differential features are regarded as autapomorphies and result in the description of the new genus Arabarpia Seizmair, gen. nov. The genus is at present monotypical, with Arabarpia albilinealis Seizmair, sp.nov. being its type-species and its only known species. The genus shares synapomorphic features with two main clades of the Scopariinae Guinée, 1854, namely the structure of the corpus bursae in the female genitalia with the clade represented by the genus Anarpia Chapman, 1912 and shape and structure of the bulbus ejaculatorius with the genus Hellenoscoparia Nuss, 1999. The latter genus belongs to another main lineage characterized by a membranous corpus bursae. The phylogenetic placement of the new genus is thus valued as ambivalent. It is not possible to resolve the ambivalent placement on the basis of the feature spaces presently known. Furthermore, the presence of the subfamily Scopariinae Guinée, 1854 is reported as new to the entomofauna of the Arabian Peninsula.
\end{abstract}

Keywords: Pyraloidea, Crambidae, Scopariinae, New Genus, New Species, Arabian Peninsula

\section{Introduction}

The Scopariinae Guinée, 1854 are among the major sub-families of the Crambidae Latreille, 1810 with a world-wide distribution. The subfamily comprises 586 known species [1-3]. The Scopariinae Guinée, 1854 were found to form a sister group complex with the Crambinae Latreille, 1810 [4].

From this sister group the Scopariinae Guinée, 1854 are distinguished by the following characteristic elements in the forewing pattern: presence of an antemedial line paired with two stigmata, namely a proximal discoidal stigma and a cubital stigma, presence of a postmedial line with a curvature opened in proximal direction paired with a distal discoidal stigma, presence of an anteterminal line forming an X-shaped structure with the postmedial line. The combination of these elements is known as the "scopariine wing pattern" and viewed as synapomorphic with regard to the Crambidae Latreille, 1810 [1, 5-7].

The basic scopariine wing pattern is subject to little variation with very few known exceptions only. Examples are the complete absence of the scopariine wing pattern, with the forewing unicolorous as is the case in the genus Afrarpia Maes, 2004 and in two species of the genus Scoparia Haworth, 1811 and the absence of the X-shaped structure formed by the postmedial and anteterminal lines, with the anteterminal area reduced to a broad unicolorous band as is the case in the genus Anarpia Chapman, 1912. The strength of contrasting of the stigmata and line elements with the ground is subject to interspecific variation $[7,8]$.

The genera of the subfamily are revised on a world-wide scale in Nuss [5]. Phylogenetic conclusions from this revision are drawn in Nuss [6]. The latter study contains a first 
cladogram of the Scopariinae Guinée, 1854 with a catalogue of apomorphic and synapomorphic features of the clades. These genus groups together with the catalogue of apomorphies and synapomorphies could be substantiated in a recent further study based on molecular genetic methods [1]. In this study further revisions were done on genus level, with three genera synonymized with Eudonia Billberg, 1820 and two genera synonymized with Scoparia Haworth, 1811. These recent revisions result in 19 known genera.

Partial revisional synopses on species level have been done for the Palearctic zone by Nuss, by Alipamah and Gianti and by Alipanah [7-9], for the Oriental and Indo-Australian zones by Nuss and by Li $[11,12]$ and for the Neotropical zone by Munroe [13, 14].

For the Afrotropical zone, a first checklist of species has been given in Maes [10]. Since then one further species has been described by Derra [15]. This results in a total of four genera and 18 species recorded up to now for the Afrotropical zone [16].

For the Arabian Peninsula, no records of Scopariinae Guinée, 1854 have been known up to now [5, 16-18].

On the Arabian Peninsula, three zoogeographical zones intersect, namely the Palearctic, Oriental and Afrotropical zones $[17,19]$.

A sample of specimens $(n=4)$ collected in the coastal mountain chain in Dhofar in the years 2018-2019 by the author is attributed to the Scopariinae Guinée, 1854 due to the presence of basic scopariine wing pattern elements and of synapomorphic feature states in the male and female genitalia.

Morphological analysis of the sample revealed differential features with regard to the type species of all the known genera of the subfamily. These features are thus regarded as apomorphic and result in the description of the new genus Arabarpia Seizmair, gen.nov. The genus is monotypical, comprising the only known species Arabarpia albilinealis Seizmair, sp.nov.

Furthermore, the presence of the Scopariinae Guinée, 1854 is reported as new to the entomofauna of the Arabian Peninsula.

\section{Material and Methods}

\subsection{Sampling}

The material presented in this paper was sampled by the author in three research expeditions to Dhofar, the south-western province of Oman in January 2018 and in February and November 2019. The collecting sites are situated on the southern slopes of the western parts of Jabal Al Qamar, a coastal mountain system ranging from the western surroundings of the province capital Salalah to the Yemen border (Figures 1-2). The specimens were captured at night by means of a light-trap equipped with a 20W tube of infra-blue light.

\subsection{Macro-Preparation and Dissection}

Macro-preparation was done on the specimens by spreading the wings and antennae. The prepared specimens were photographed with a SONY HX400V camera.
For examining the genitalia, dissection, preparation and slide-mounting techniques were applied on the specimens on the basis of the protocol described in Robinson [20]. The slides were photographed with a SONY DSC100V camera under a 40x zoom.

The forewing and hindwing venations were extracted by mounting the forewing in euparal. The resulting slide was photographed under a 20x zoom. The images were optimized by means of the software Ps Adobe Photoshop, Version 21.0.2.

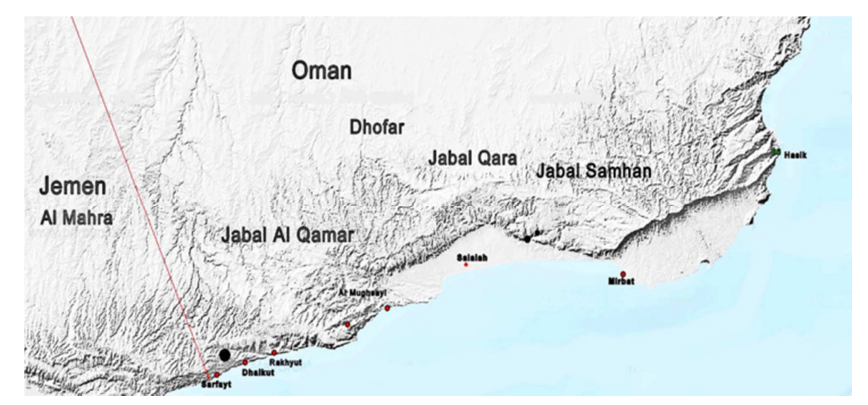

Figure 1. Type Locality in Oman, Dhofar, Jabal Al Qamar, near the Yemen border (black point).

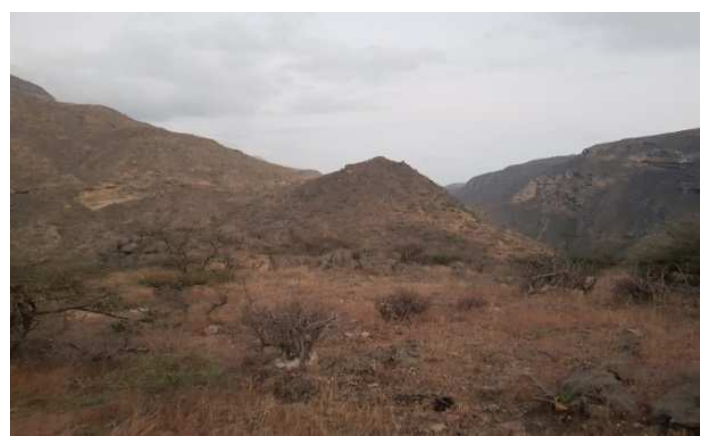

Figure 2. Type Habitat in Oman, Dhofar, Jabal Al Qamar.

\subsection{Morphometric Analyses}

Morphometric analyses of wing patterns and genital-morphological structures were done on the images. Structural ratios were measured and calculated by means of the imaging software ZEISS AxioVision, Version 4.8.

\subsection{Terminology and Abbreviations}

The descriptions of the genitalia and tympanal organs are based on the terminology in Maes and in Nuss and Speidel [21-23]. The descriptions of the wing patterns and of the venations are based on the terminology in Nuss [5-7]. The feature states referred to in the descriptions are based on the feature spaces given in Léger, Landry, and Nuss and in Nuss [1, 6].

Abbreviations:

ZSM Zoological State Collection Munich, Germany.

\section{Results}

\subsection{Descriptions of New Taxa}

Arabarpia Seizmair, gen.nov. (Figures 3-9)

Type species: Arabarpia albilinealis Seizmair, sp.nov. 
External features (Figures 3-6): Head: Clypeus present. Eyes compound, ocelli and chaetosemata present. Frons and vertex evenly rounded. Antennae filiform, flagellomeres of males cylindrical, of females slightly prismatic. Labial and maxillary palpus upright, ratio between the length of the labial palpus and the diameter of the eye $1 / 1$, ratio between the length of the maxillary palpus and the length of the labial palpus 1 / 3. Number of spurs on fore-middle-hindlegs 2-0-4, as is typical of the Pyraloidea.

Forewing: Wing pattern with basic elements of the scopariine wing pattern: antemedial and postmedial lines and the proximal discoidal, distal discoidal and cubital stigmata present, yet with the anteterminal line missing. Anteterminal area reduced to a broad unicolorous band. Basal, medial and postmedial areas unicolorous (Figure 3). Terminal points of Sc, $\mathrm{R} 1, \mathrm{R} 2$ and $\mathrm{R} 3$ on the costal border equidistant, $\mathrm{R} 4$ ending on the termen closely below the apex, R5 ending in the distal fifth of the termen. Ratio between the distances of the bases of R5-M1 / M2-M3 1 / 1,8 (Figure 4). Frenulum single in the male, double in the female.

Hindwing: Basal and medial areas unicolorous, postmedial and anteterminal areas significantly darker. Discoidal cell open. M1-Sc+Rs connection in the first proximal fifth of the discoidal cell. Rs ending at the end of the first eighth of the termen below the apex. Ends of the M-veins on the termen equidistant. M2 and M3 relatively long stalked, the stalking point at the end of the first distal third of the hindwing. Ratio between the distances between the end points on the termen $\mathrm{Cu} 1-\mathrm{Cu} 2 / \mathrm{Cu} 2-\mathrm{CuP} 1 / 2,5$ (Figure 5).

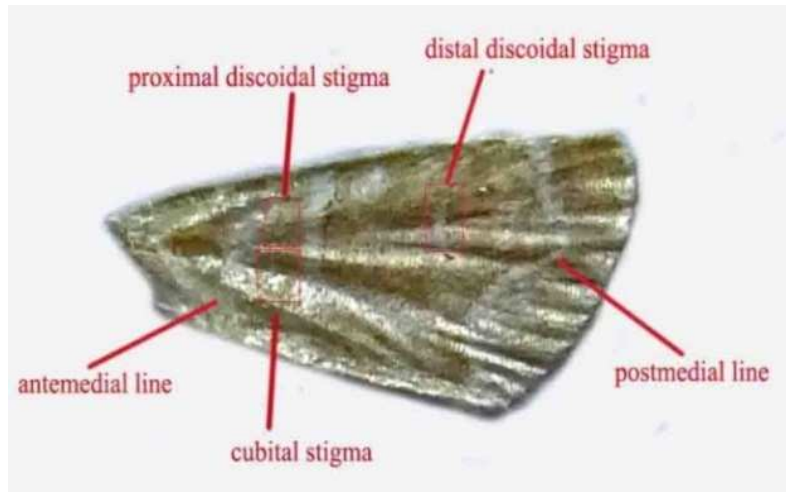

Figure 3. Basic forewing pattern of the genus Arabarpia Seizmair, gen.nov.

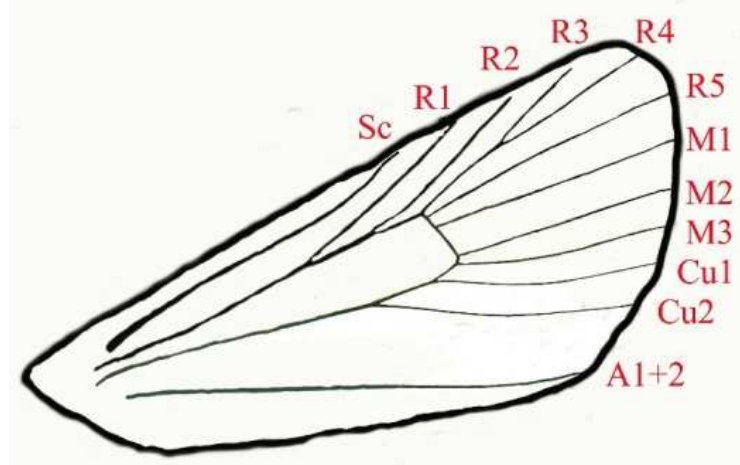

Figure 4. Forewing venation of the genus Arabarpia, Seizmair, gen.nov.

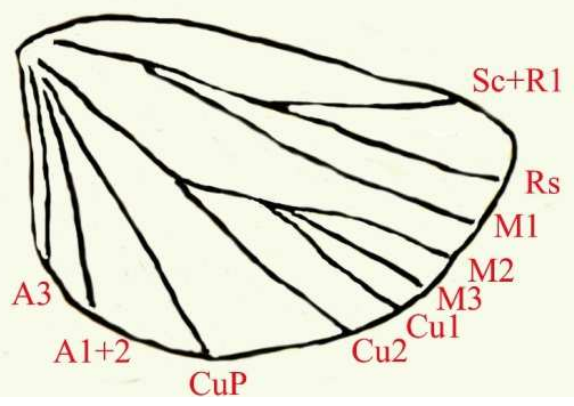

Figure 5. Hindwing venation of the genus Arabarpia, Seizmair, gen.nov.

Male genitalia (Figure 6): Uncus triangular, strongly sclerotized supero-laterally, dorsally with long setae, acute distally. Gnathos pointed upwards, strongly sclerotized, rounded distally, of constant width, finger-shaped, equal in length with the uncus. Base of the gnathos with a sclerotized diverticulum on the anterior border pointing in proximal direction.

Tegumen ventro-laterally with strongly sclerotized arms, dorso-laterally with a significant concavity. Valva without ventral projection, divided into dorsal and ventral halves by an elongate, straight sclerotization developing from the base and extending into the distal third, with a bifurcation at the distal end, one part of the bifurcation pointing in costal, the other part pointing in dorsal direction. Valva strongly tapering distally, with an elongate membranous apical area occupied with several long, strongly sclerotized setae supero-laterally. Proximal area of the valva with strongly sclerotized setae of variable length on the ventral and dorsal borders and in the interior. Sacculus acute, pointed proximally, with the proximal point slightly sclerotized.

Juxta plate-like, strongly broadened and elongate. Transtillum arms unconnected, strongly developed, with projections of ellipsoid shape on each side.

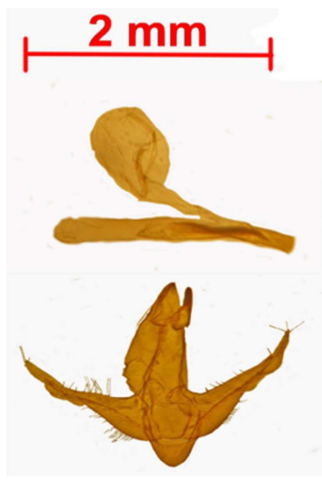

Figure 6. Holotype, male genitalia, Arabarpia albilinealis Seizmair, gen.nov., sp.nov., slide no. 20 GP030.

Aedeagus with an arc-shaped cornutus extending from the distal portion into the ceacum. Ductus ejaculatorius opening distad from the middle of the phallus. Bulbus ejaculatorius with strong lateral sclerites forming a closed ovoid shaped vessel, furthermore with strongly developed, stroke-shaped sclerites in the interior.

Female genitalia (Figure 7): Papillae anales triangular, 
strongly sclerotized in the interior and occupied with several tufts of long setae supero-laterally. Apophyses anteriores and apophyses posteriores equal in length, bare of any projections. Ratio between the length of the apophyses anteriores and the length of the papillae anales $1 / 0,69$. VII tergit with several U-shaped sclerites antero-medially.

Ostium orbiform. Antrum with an extensive triangular-shaped prolongation, with the apex pointing downwards in proximal direction and with lateral sclerites and scales in the distal portion.

Ductus bursae with an elongate stroke-loke sclerite in the interior of its distal third paired with sclerotizations on the borders, colliculum relatively short, making up $12 \%$ of the total length of the ductus bursae, with strong lateral sclerotizations. Ductus seminalis inserted immediately at the proximal end of the colliculum.

Bursa copulatrix without appendix bursae, with a signum consisting of a strong, stroke-like sclerite strongly broadened at the end in the interior of the bursa with stroke-like lateral projections forming a $90^{\circ}$-angle and scobinate patches on both sides, which are slightly asymmetrical and separated from the rest of the corpus bursae by a broad, flange-like sclerotized ridge. The signum and the scobinate patches cover roundabout $80 \%$ of the wall of the bursa. The other membranous part is interspersed with numerous fine thorn-shaped sclerites of varying shape and size.

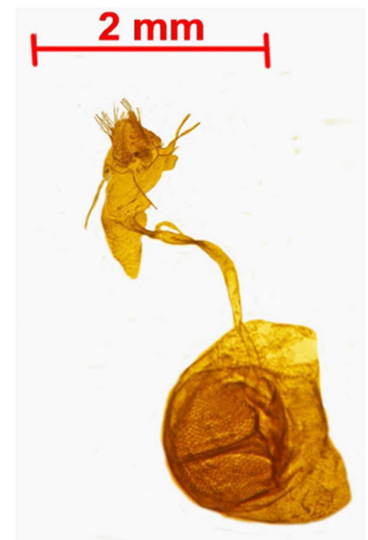

Figure 7. Paratype, female genitalia, Arabarpia albilinealis Seizmair, gen.nov., sp.nov., slide no. 20 GP029.

Tympanal organs (Figure 8): Ratio between the maximum width and the maximum length of the ala tympani $1 / 1,8$, costal borders of the ala tympani strongly concave near the pons tympani, concavity strongly sclerotized. Pons tympani of constant width. Tergo-sternal sclerite straight, of constant strength, rounded distally. Lobuli semi-circular. Bullae tympani reniform, as is typical of the Scopariinae Guinée, 1854, elongate, ratio between the maximum width and the maximum length $1 / 2$. Sacci tympani elongate, triangular-shaped, ratio between the maximum width and the maximum length $1 / 1,5$, borders strongly sclerotized. Venulae secundae well developed, running parallel to the body axis. Rami tympani absent. Puteoli tympani present, very small, u-shaped, slightly asymmetric.

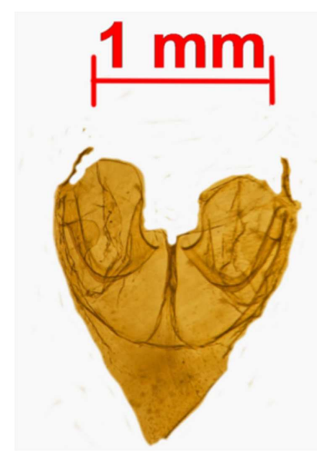

Figure 8. Paratype, tympanal organs, Arabarpia albilinealis, Seizmair, gen.nov., sp.nov., slide no. 20 GP029.

Differential diagnosis: The genus closest to the new genus is Anarpia Chapman, 1912. The female genitalia of these two genera share the absence of the appendix bursae, the elongate signum in the corpus bursae paired with strongly sclerotized scobinate patches on each side, the triangular-shaped papillae anales, the short colliculum of constant width with strong lateral sclerotizations and the prolongation of the antrum.

The new genus differs from the closely related Anarpia Chapman, 1912 in the following features, which make the genus unique also with regard to all the other known genera. These features are thus regarded as apomorphic.

In the female genitalia, the new genus differs from the other known genera in the arc-shaped sclerite in the interior of the ductus bursae proximad of the colliculum and the strongly sclerotized flange-like ridge delimiting the scobinate patches from the rest of the corpus bursae.

The male genitalia show the following apomorphic features: the sclerite dividing the valva into dorsal and ventral halves with a bifurcation at the distal end, the strongly tapering apical area of the valva with long, strongly sclerotized setae on the tip of the apex, the finger-shaped gnathos, the ellipsoid projections of the transtillum arms and the sclerites in the interior of the bulbus ejaculatorius.

Diversity and distribution: The new genus is monotypical. Its presently known distribution is restricted to the mountain systems in the province Dhofar of Oman.

Etymology: The prefix "Arab-"of the genus epitheton refers to the Arabian Peninsula, the suffix "-arpia" refers to the genus Anarpia Chapman, 1912, to which the new genus is closely related. The gender of the genus is feminine.

Arabarpia albilinealis Seizmair, sp. nov.

Material: Holotype: đ̃, Oman, Dhofar, $20 \mathrm{~km}$ E Sarfait, Jebel Al Qamar, 960 m, 03-II-2019, leg. M. Seizmair, coll. ZSM, slide no. 20GP030. Paratypes: Oman, Dhofar, $20 \mathrm{~km} \mathrm{E}$ Sarfait, Jebel Al Qamar, 960 m, 25-XI-2019, 1 , , slide no.

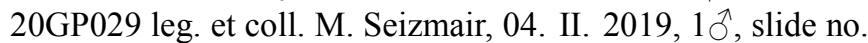
20GP033, 20. I. 2018, 1§̂, slide no. 20GP034, leg. et coll. M. Seizmair.

External features (Figure 9): Wingspan of the holotype: 23,1 $\mathrm{mm}$, forewing length of the holotype: 11,6 $\mathrm{mm}$. Wingspans of the paratypes: $20,9-21,8 \mathrm{~mm}$, forewing lengths of the paratypes: 9,3-10,8 mm. Head: Scaling of the frons and the vertex constantly greyish-white. Dorsal scaling of the clypeus greyish white, ventral scaling black. Antennae 
with black flagellum, flagellomeres and sensillae trichodeae scaled whitish-grey. Labial palpus of constant width in the segments 1 and 2, strongly tapering in segment 3, acute distally, elongate, 2,8 times as long as wide, basic scaling sporadically greyish interspersed with darkish-brown scales, tip of segment 3 with black scales. Scaling of the labial palpus greyish-white interspersed with darkish-brown scales on the lateral borders. Thorax: Dorsal basic scaling of the prothorax darkish-grey, laterally with two longitudinal black strokes, meso-and metathorax irregularly interspersed with darkish-brown scales, ventral scaling of the entire thorax ochre sporadically interspersed with whitish-grey scales. Tegula greenish interspersed with greyish-white scales. Legs with the dorsal scaling of the femur greyish to darkish-ochre, the dorsal scaling of the tibia darkish-brown to black interspersed with greyish scales, ventral scaling of the legs constantly greyish-white. Abdomen: Dorsal basic scaling greyish irregularly interspersed with darkish-green scales, lateral and ventral scaling greyish-white, with a clearly distinct triangular-shaped field of black scales laterally on the segments A2 and A3.

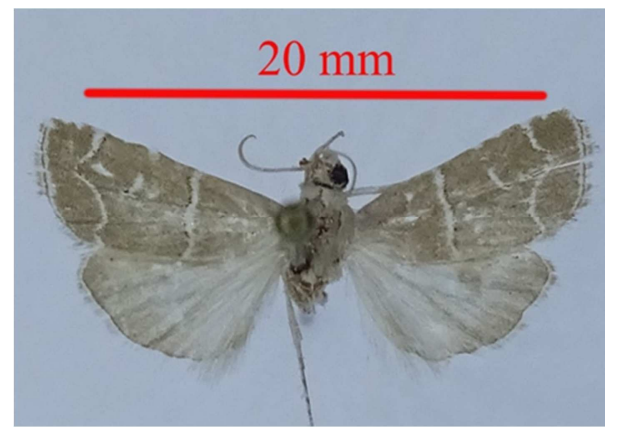

Figure 9. Holotype, male adult, Arabarpia albilinealis Seizmair, gen.nov., sp.nov., abdomen separated for dissection.

Forewing: Upper side: Ground scaling greenish, sporadically interspersed with darkish-grey scales. Antemedial and postmedial lines white, clearly distinct from the ground. Medial area with an additional white transversal line, running straight from the costal to the anal border. Each of the three transversal lines is bordered by rows of small black points on each side. Cubital stigma orbiform, proximal discoidal stigma ovoid, both bordered with greenish to darkish-grey scales, with the kernel greenish-fuscous. Distal discoidal stigma elongate, with a white jota-shaped kernel with greyish-fuscous border. Each of the three stigmata contrasts weakly with the ground. Anteterminal area with a broad band unicolorous with the ground and sporadically interspersed with fuscous fasciae apically and sub-apically. Termen white. Fringe darkish-fuscous in the proximal part, greyish-green in the distal part. Underside with the same pattern as the upper side, ground whitish-grey to whitish-green, cubital and proximal discoidal stigmata darkish-grey, weakly contrasted with the greyish ground, distal discoidal stigma reduced to an eight-shaped structure with a light-grey kernel, and greenish-grey border.

Hindwing: Upper side: Basal and medial areas scaled greyish white interspersed with black scales along the anal, cubital and medial veins. Postmedial and anteterminal areas darkish-fuscous, termen darkish-brown to black, fringe as in the forewing. Underside like upper side.

Male genitalia (Figure 6): Uncus 1,4 times as long as wide. Gnathos equal in width with its base. Ventral border of the valva strongly concave at the base, then running straight up to another concavity subapically. Dorsal border with a short convexity at the base, then running straight. The apical area makes up $25 \%$ of the total length of the valva, its interior interspersed with small spine-like sclerites. Sacculus triangular-shaped. Juxta trapezoid, ratio between height and width $1 / 1$. Projections of the transtillum arms asymmetrical, the left one orbiform, the right one ovoid and double as long as wide. Saccus triangular-shaped, rounded proximally, double as wide as long. The sclerites in the interior of the bulbus ejaculatorius form an X-shaped structure. Ratio between width and length of the bulbus ejaculatorius $1 / 1,4$, with the length equal with $40 \%$ of the total length of the aedeagus (caecum + distal portion). Ratio between the length of the ductus ejaculatorius and the length of the bulbus ejaculatorius $1 / 1,25$.

Female genitalia (Figure 7): Papillae anales strongly broadened, as long as wide. Ductus bursae very slender, with its length equal with the maximum length of the corpus bursae. Corpus bursae elongate, asymmetric in shape, semi-ovoid.

Bionomics: The types were collected in the montane zone on the border of an escarpment interspersed with rocks (Figure 2). The type habitat is typical of the Scopariinae Guinée, 1854 [5, 21]. The life cycle and the premature stages are unknown.

Etymology: The species epitheton refers to one of the characteristic features of the forewing pattern, the white antemedial, medial and postmedial lines (lat.: albus $=$ white, linea $=$ line).

\subsection{Discussion: Phylogenetic Placement of the New Genus}

The Scopariinae Guinée, 1854 consist of two main groups of genera. This division is based on the structure of the corpus bursae $[1,5,6]$. The corpus bursae wall of the first group comprising Scoparia Haworth, 1811 + Eudonia Billberg, 1820+ Sineudonia Leraut, 1986 + Gibeauxia Leraut, $1988+$ Micraglossa Warren, 1891 + Touloetodes Leraut, $1988+$ Witlesia Chapman, 1911 is divided into one half of scobinate patches and another half covered with fine spines. The presence or absence of a streak-like signum is subject to inter-generic variation. This structure of the corpus bursae is hypothesized to be synapomorphic in Nuss [5, 6]. The synapomorphy of this feature is further substantiated by the computational results in Léger, Landry, and Nuss [1]. This main group contains a subgroup comprising Scoparia Haworth, 1811 + Eudonia Billberg, 1820 + Sineudonia Leraut, 1986 characterized by the presence of an appendix bursae. In all the other genera including the new genus the appendix bursae is absent.

The other main group of genera is subdivided into a 
subgroup of genera with the corpus bursae membranous Helenoscoparia Nuss, 1999 + Antiscopa Munroe, $1964+$ Iranarpia Leraut, $1982+$ Syrianarpia Leraut, $1982+$ Hoenia Leraut, 1986 + Pagmanella Leraut, 1985 and another subgroup with the corpus bursae consisting of an elongate signum with scobinate patches on each side comprising Cosipara Munroe, 1972 + Anarpia Chapman, $1912+$ Gesneria Huebner [1825].

The new genus Arabarpia Seizmair, gen.nov. shares with the latter subgroup the signum with extensive scobinate patches on the corpus bursae wall. This feature is regarded as a synapomorphy in Nuss [6]. Yet, the new genus is distinguished from the other members of this group and all the other genera by the strongly sclerotized flange-like ridge bordering the scobinate patches and the sclerite in the ductus bursae proximad from the colliculum. In the male genitalia, a strong sclerite in the valva developing distad from the sacculus comparable to that of the new genus is shown by the neotropical genus Cosipara Munroe, 1972. Yet, the sclerite in the valva of the new genus differs from the sclerite in Cosipara Munroe, 1972 significantly in shape: In Cosipara Munroe, 1972 the sclerite shows a $90^{\circ}$ curvature in the proximal fourth and is directed towards the dorsal border. In the new genus Arabarpia Seizmair, gen.nov. the sclerite in the valva is straight, directed towards the apical area and with a bifurcation in the distal fifth.

On the other hand, the new genus Arabarpia Seizmair, gen.nov shares a synapomorphy with the genus Hellenoscoparia Nuss, 1999, to wit the large bulbus ejaculatorius with lateral sclerites forming an ovoid vessel. Hellenoscoparia Nuss, 1999 belongs to the subgroup of genera characterized by a membranous corpus bursae wall.

The placement of the new genus in the overall phylogenetic system of the Scopariinae Guinée, 1854 is thus to be valued as ambivalent. The new genus shares synapomorphic feature states with the group of genera characterized by a membranous corpus bursae wall and also with the group of genera characterized by a signum with scobinate patches on the corpus bursae wall. The ambivalent placement of the new genus should be regarded as on a par with the ambivalent placement of the genus Afroscoparia Nuss, 2003: Both Afroscoparia Nuss, 2003 and the new genus share the shape of the bulbus ejaculatorius with the genus Hellenoscopria Nuss, 1999. On the other hand, the corpus bursae wall of Afroscoparia Nuss, 2003 is divided into a spinose and spatulate half with the appendix bursae present. The genus Afroscoparia Nuss, 2003 thus also shares features with the main lineage represented by Scoparia Haworth, 1811. It is not possible to resolve the ambivalent placements of the new genus and of Afroscoparia Nuss, 2003 by the morphological features known at present [6].

Furthermore, the phylogenetic relation of the new genus with the genus Afrarpia Maes, 2004 is in need of further clarification. Afrarpia Maes, 2004 is claimed to be closely related to Anarpia Chapman, 1912 [8]. Yet, the only synapomorphy presently known shared between Anarpia Chapman, 1912 and Afrarpia Maes, 2004 is the absence of the appendix bursae. Anarpia Chapman, 1912 and the new genus are clearly differentiated from Afrarpia Maes, 2004 by a signum paired with scobinate patches on the corpus bursae wall. The corpus bursae wall of the genus Afrarpia Maes, 2004 is characterized by the absence of a signum. For a further understanding of the relations between Afrarpia Maes, 2004, the new genus and the Anarpia Chapman, 1912 group, study of the male genitalia of Afrarpia Maes, 2004 is needed. The male genitalia of Afrarpia Maes, 2004 are still unknown.

\section{Conclusion}

In this paper occurrences of the Scopariinae Guinée, 1854 are reported for the entomofauna of the Arabian Peninsula for the first time. The specimens are attributed to a new genus Arabarpia Seizmair, gen.nov. consisting of the only species Arabarpia albilinealis Seizmair, sp.nov. at present.

Further undescribed species are expected to be discovered in further field research in the coastal mountain systems of the Southern Arabian Peninsula ranging over the coastal line of Dhofar and Yemen and in the Asir mountain system in the extreme west of Yemen and south-western Saudi-Arabia. These mountain ranges are still unexplored for the Scopariinae Guinée, 1854.

The distributional status of the new genus is still in need of clarification. The Scopariinae Guinée tend to endemic diversification, i.e. splitting up into endemic genera, such as Hellenoscoparia Nuss, 1999, and endemic speciation [24]. Endemism to the coastal mountain range of Dhofar and Yemen as well as still unknown occurrences of the new genus on the African Continent are both thinkable with regard to the present state of knowledge.

\section{Acknowledgements}

The author thanks Eva Karl (SNSB / ZSM, Munich, Germany), Andreas Segerer (SNSB / ZSM, Munich, Germany) and Gerhard Haszprunar (SNSB / ZSM, Munich, Germany) for technical support in his field research and in the compilation of the manuscript. Furthermore, the author thanks Rudi Verovnik, Gordana Glavan (Biotechnical Faculty, University of Ljubljana, Slovenia), Peter Valič (Advoš́čina, Slovenia) and Marko Kosmač (Advoš́čina, Slovenia) for shared field expeditions to Dhofar (Oman) in January 2018 and November 2019.

\section{References}

[1] T. Léger, B. Landry, and M. Nuss, "Phylogeny, character evolution and tribal classification in Crambinae and Scopariinae (Lepidoptera, Crambidae), Systematic Entomology, vol 44, pp. 757-776, 2019.

[2] M. Nuss, B. Landry, R. Mally, F. Vegliante, A. Tränkner, F. Bauer, J. Hayden, A. Segerer, R. Schouten, H. Li, T. Trofimova, M. A. Solis, J. De Prins and W. Speidel, "Global Information System on Pyraloidea," World Wide Web electronic publication (http://www.pyraloidea.org) [30.09.2020]. 
[3] T. Léger, R. Mally, C. Neinhuis, M. Nuss, "Refining the phylogeny of Crambidae with complete sampling of subfamilies (Lepidoptera, Pyraloidea)," Zoologica Scripta, Early View, pp. 1-16, 2020.

[4] J. C. Regier, C. Mitter, M. A. Solis, "A molecular phylogeny for the pyraloid moths (Lepidoptera: Pyraloidea) and its implications for higher-level classification," Systematic Entomolgy, vol. 37, pp. 355-364, 2012.

[5] M. Nuss, "Revision of the genera of the Scopariinae (Lepidoptera: Pyraloidea, Crambidae)," Nova Supplementa Entomologica, vol 13, pp. 3-151, December 1999.

[6] M. Nuss, "Afroscoparia - a new genus of Scopariinae from southern Africa (Insecta: Lepidoptera: Pyraloidae: Crambidae)," Entomologische Abhandlúngen, vol. 61 (1), pp. 109-115, 2003.

[7] M. Nuss, "Subfamily Scopariinae," in Pyraloidea, vol. I, B. Goater, M. Nuss and W. Speidel, Eds. Stenstrup: Apollo Books, 2005, pp. 127-181.

[8] H. Alipanah and M. Gianti, "A review of the genus Syrianarpia Leraut (Crambidae, Scopariinae) with description of $S$. elburzalis sp.n. from Iran,”Zootaxa, vol. 4365 (4), pp. 495-499, 2017.

[9] H. Alipanah, "New and little known species of Scopariinae (Lepidoptera: Crambidae) from Iran," Journal of Entomological Society of Iran, vol. 37 (4), pp. 529-542, 2018.

[10] K. V. N. Maes, "New Scopariinae from Eastern and Southern Africa (Lepidoptera, Pyraloidea, Crambidae)," Journal of Afrotropical Zoology, vol. 1, pp. 57-71, 2004.

[11] M. Nuss, "The Scopariinae and Heliothelina stat. rev. (Lepidoptera: Pyraloidea, Crambidae) of the Oriental Region a revisional synopsis with descriptions of new species from the Philippines and Sumatra," Nachrichten des Entomologischen Vereins Apollo, vol 17 (Suppl.), pp. 475-528, 1998.

[12] W. Li, "Integrative Taxonomy reveals the exceptional species diversity of Eudonia (Lepidoptera, Crambidae) in Tibet, China," Systematics and Biodiversity, vol. 17 (1), pp. 39-50, 2019.

[13] E. G. Munroe, "Pyraloidea, Pyralidae comprising subfamilies Scopariinae, Nymphulinae," in The Moths of America north of Mexico, R. B. Dominick, Ed. London: W. Classey and R. B. D. Publications Inc., 1972, pp. 1-134.

[14] E. G. Munroe, "Crambidae (Crambinae, Schoenobiinae, Cybalominae, Linostinae, Glaphyriinae, Dichogaaminae, Scopariinae, Musotiminae, Midilinae, Nymphulinae, Odontiinae, Evergestinae, Pyraustinae)," in Atlas of Neotropical Lepidoptera. Checklist: Part 2, Hyblaeoidea -
Pyraloidea - Tortricoidea, Vol 3, J. B. Heppner, Ed. Gainesville, Florida: Association for Tropical Lepidoptera \& Scientific Publishers, 1995, pp. 34-79.

[15] G. Derra, "Description of the new species Eudonia fogoalis spec.nov. from the Cape Verdean Islands (Lepidoptera: Crambidae, Scopariinae),“ Esperiana, vol. 14, pp. 595-597, 2008.

[16] J. De Prins and W. De Prins. "Afromoths, online database of Afrotropical moth species (Lepidoptera)," World Wide Web electronic publication (http://www.afromoths.net) [30.09.2020].

[17] J. E. F. Asselbergs, "Order Lepidoptera, superfamily Pyraloidea," in Arthropod fauna of the United Arab Emirates, Volume 1, Harten, A. van, Ed. Abu Dhabi: Dar Al Ummah Printing, Publishing, Distribution \& Advertising, 2008, pp. 469-561.

[18] S. Ratnasingham, "BOLD Barcode of Life Data System," World Wide Web electronic publication (https://www.boldsystems.org/index.php/Public_BINSearch?s earchtype=records? search='Scopariinae') [30.09.2020].

[19] H. Hacker, "Systematic and Illustrated Catalogue of the Macrohetrocera and Cossioidea, Zygaenoidea, Thyridoidea and Hyblaeoidea of the Arabian Peninsula, with a survey of theit distribution (Lepidoptera)," in Esperiana, Vol. 20, H. Hacker, Ed. Schwanfeld, Germany: Publishing Company H. Peks, 2016, pp. 1-743.

[20] G. Robinson, "The Preparation of Slides of Lepidoptera Genitalia with Special Reference to the Microlepidoptera," Entomologist's Gazette, vol. 27, pp. 127 - 132, 1976.

[21] K. V. N. Maes, "A comparative study of the abdominal tympanal organs in Pyralidae (Lepidoptera). I. Description, terminology, preparation technique," Nota Lepidopterologica, vol. 8 (4), pp. 341-350, 1985.

[22] K. V. N. Maes, "A comparative morphological study of the adult Crambidae (Lepidoptera, Pyraloidea)," Bulletin et Annales de la Société Royale Entomologique de Belgique, Bruxelles, vol. 131, pp. 383-434, 1995.

[23] M. Nuss and W. Speidel, "Introduction," in Pyraloidea, vol. I, B. Goater, M. Nuss and W. Speidel, Eds. Stenstrup: Apollo Books, 2005, pp. 1-32.

[24] E. G. Munroe and M. A. Solis, "The Pyraloidea, Lepidoptera, Moths and Butterflies. Volume 1: Evolution, systematics, and biogeography," in Handbook of Zoology, Vol. IV Arthropoda: Insecta, M. Fischer Ed. Berlin, Germany: Walter de Guyter, 1998, pp. 233-256. 